\title{
Effects of processing parameter on energy storage density and ferroelectric properties of lead-free bismuth sodium titanate-strontium bismuth titanate ceramics
}

\author{
Kamonporn Saenkam ${ }^{\mathrm{a}, \mathrm{b}}$, Pharatree Jaita ${ }^{\mathrm{a}, \mathrm{c}}$, Somnuk Sirisoonthorn ${ }^{\mathrm{d}}$, Tawee Tunkasiri ${ }^{\mathrm{a}, \mathrm{e}}$, \\ Gobwute Rujijangul ${ }^{\mathrm{a}, \mathrm{c}, \mathrm{e}, \mathrm{f}, *}$ \\ a Department of Physics and Materials Science, Faculty of Science, Chiang Mai University, Chiang Mai \\ 50200 Thailand \\ b Graduate School, Chiang Mai University, Chiang Mai 50200 Thailand \\ c Science and Technology Research Institute, Chiang Mai University, Chiang Mai 50200 Thailand \\ d National Metal and Materials Technology Center, Thailand Science Park, Pathum Thani 12120 Thailand \\ e Materials Science Research Center, Faculty of Science, Chiang Mai University, Chiang Mai 50200 \\ Thailand \\ ${ }^{\mathrm{f}}$ Research Center in Physics and Astronomy, Faculty of Science, Chiang Mai University, Chiang Mai 50200 \\ Thailand
}

*Corresponding author, e-mail: rujijanagul@yahoo.com

Received 10 Nov 2020

Accepted 16 Apr 2021

\begin{abstract}
In order to clarify the optimal sintering conditions, the effects of processing parameter on phase evolution, physical, microstructure, dielectric, ferroelectric, and energy storage density properties of bismuth sodium titanatestrontium bismuth titanate ceramics (or BNT-SBT) were investigated. The studied ceramics were fabricated via a conventional mixed oxide method and sintered at temperatures ranging from $1100-1175^{\circ} \mathrm{C}$ under normal atmosphere for $3 \mathrm{~h}$ dwell time with a heating/cooling rate of $5^{\circ} \mathrm{C} / \mathrm{min}$. The XRD data revealed that the coexisting rhombohedral and tetragonal phases were observed in all of the ceramics. With increasing sintering temperature, the cubic-rich phase was dominated; and the average grain size tended to increase. For the ceramics sintered at $1150^{\circ} \mathrm{C}$, the good density $\left(5.74 \mathrm{~g} / \mathrm{cm}^{3}\right)$, dielectric $\left(\varepsilon_{\max }=3510, \tan \delta=0.0501, T_{\mathrm{F}-\mathrm{R}}=73.80^{\circ} \mathrm{C}, T_{\mathrm{m}}=273^{\circ} \mathrm{C}\right)$, and ferroelectric $\left(P_{\mathrm{r}}=3.05\right.$ $\mu \mathrm{C} / \mathrm{cm}^{2}, E_{\mathrm{c}}=7.69 \mathrm{kV} / \mathrm{cm}$ ) were obtained. In addition, the obtimum sintering temperature of $1150^{\circ} \mathrm{C}$ was also found to improve the energy storage density properties $\left(W=0.94 \mathrm{~J} / \mathrm{cm}^{3}, \eta=89.93 \%\right.$ at $125^{\circ} \mathrm{C}$, and $\left.E=E_{\max }\right)$.
\end{abstract}

KEYWORDS: sintering temperature, lead-free ceramics, dielectric and ferroelectric properties, energy storage density

\section{INTRODUCTION}

Materials with high energy storage density $(W)$ and high energy storage efficiency $(\eta)$ are desired to meet the growing requirements for compact electrics and devices $[1,2]$. Among the various electrical energy storage materials, dielectric ceramics are widely studied for their excellent energy storage performance [3]. Ceramic-based dielectric capacitors have drawn growing interest due to their small volume, excellent thermal properties, good mechanical properties, fast charge-discharge speed, and high-power density [4]. Besides, large maximum polarization $\left(P_{\max }\right)$ and low remnant polarization $\left(P_{\mathrm{r}}\right)$ in the relaxor ferroelectrics are key features for $W$ and $\eta$ in the selection of materials [5].
The bismuth sodium titanate $\left(\mathrm{Bi}_{0.5} \mathrm{Na}_{0.5} \mathrm{TiO}_{3}\right.$ or $\mathrm{BNT}$ ) has been identified as a potential energy storage material because it has a large spontaneous polarization $\left(P_{s}\right)$ over $40 \mu \mathrm{C} / \mathrm{cm}^{2}$ [6], which originates from the hybridization of $\mathrm{Bi} 6 \mathrm{p}$ and $\mathrm{O} 2 \mathrm{p}$ orbitals [4]. However, the BNT has large $P_{\mathrm{r}}$ at ambient temperature and high coercive field $\left(E_{\mathrm{c}} \sim 73 \mathrm{kV} / \mathrm{cm}\right)[6,7]$, which limit its energy storage density resulting in a small recoverable energy storage density $\left(W_{\text {rec }}\right)$ and a low $\eta$ values $[4,8,9]$. The BNT-based ceramics have also been widely used in the energy-storage devices because their permittivity and polarization are higher than other linear dielectrics [10]. For the sake of promoting the energy storage properties with decreasing $P_{\mathrm{r}}$ value, the modulation of BNT by other perovskite compositions was identified [9]. 
Strontium bismuth titanate $\left(\mathrm{Sr}_{0.7} \mathrm{Bi}_{0.2} \mathrm{TiO}_{3}\right.$ or $\mathrm{SBT}$ ) is a relaxor ferroelectric with perovskite structure, which possesses several advantages for energy storage [11]. SBT ceramics exhibit good relaxor ferroelectric behavior and a diffused dielectric maximum in a wide range of temperatures, resulting from the Sr site vacancy and the off centered $\mathrm{Bi}^{3+}$ ion [11]. The SBT ceramics show relaxation behavior, which is essentially caused by the dipolar interaction [12]. Qiao et al [4] studied the energy density and thermal stability properties of relaxor ferroelectric BNT-SBT ceramics. In their study, the SBT was introduced into the BNT ceramic via a standard solid-state route to modulate its relaxation behavior and energy storage performance. With increasing SBT content, the perovskite structure of BNT transformed from a rhombohedral phase to a weakly polarized pseudo-cubic phase, and the relaxation behavior was enhanced. In particular, the dielectric breakdown strength $\left(E_{\mathrm{DBS}}\right)$ was improved from $120 \mathrm{kV} / \mathrm{cm}$ (of the pure BNT ceramic) to around $160 \mathrm{kV} / \mathrm{cm}$ (of the 0.6BNT-0.4SBT ceramic), which displayed a large $W_{\text {rec }}$ of $2.20 \mathrm{~J} / \mathrm{cm}^{3}$, implying a large potential ability of the 0.6BNT0.4 SBT ceramic in energy storage [4]. Li et al [5] also found a significant increase of $W\left(1.5 \mathrm{~J} / \mathrm{cm}^{3}\right)$ and $\eta(73 \%)$ for the BNT-SBT ergodic relaxor (ER) ceramics. The significant increase of $W$ was due to the ceramics' low $P_{\mathrm{r}}$ and large $P_{\max }$, which were induced by adding SBT into the $(1-x) \mathrm{Bi}_{0.5} \mathrm{Na}_{0.5} \mathrm{TiO}_{3}$ $x \mathrm{Sr}_{0.85} \mathrm{Bi}_{0.1} \mathrm{TiO}_{3}$ ceramic. Ang and $\mathrm{Yu}$ [13] have also reported that the BNT-SBT relaxor ferroelectrics exhibit a very high ferroelectric polarization and a high purely electrostrictive strain. Therefore, it can be reasonably expected that the ER state, with low $P_{\mathrm{r}}$, combined with large $P_{\max }$, induced by SBTdoping BNT ceramics, might improve the energystorage properties of the BNT-SBT ceramics.

According to the above study reports, it could say that the SBT plays an important role in improving the $W_{\text {rec }}$ of BNT-based system. In the present study, we selected the BNT with excellent piezoelectric as base material, and a small amount of SBT was added as additive at the composition of 0.7BNT-0.3SBT ceramics (which showed interesting electrical properties, i.e the $W$ ) $[4,10]$. Moreover, as sintering process is important for fabrication of ceramic materials [14], the effects of sintering temperatures on the densification, phase, microstructure, dielectric, ferroelectric, and $W$ were investigated and discussed in details. It was expected that the optimum sintering condition could produce ceramics with better properties.

\section{MATERIALS AND METHODS}

The lead-free 0.7BNT-0.3SBT ceramic was prepared by the conventional mixed-oxide method. Analytical grade reagents of $\mathrm{Bi}_{2} \mathrm{O}_{3}, \mathrm{Na}_{2} \mathrm{CO}_{3}, \mathrm{TiO}_{2}$, and $\mathrm{SrCO}_{3}$ were used as the starting raw materials. All carbonate powders were dried at $120^{\circ} \mathrm{C}$ for $24 \mathrm{~h}$ to remove any moisture. The 0.7BNT-0.3SBT obtained was stoichiometrically weighed and mixed by ball milling in $99.9 \%$ ethanol for $24 \mathrm{~h}$, and the slurry was dried in an oven. The resulted mixed powder was calcined in air atmosphere at $850^{\circ} \mathrm{C}$ for $3 \mathrm{~h}$ dwell time. A few drops of $4 \mathrm{wt} \%$ polyvinyl alcohol binders were added to the mixed powder, which was then uniaxially pressed into disc pellets (10 $\mathrm{mm}$ in diameter and about $1.2 \mathrm{~mm}$ in thickness), or the ceramics, to be used as ceramic samples. The ceramics were sintered at $1100,1125,1150$, and $1175^{\circ} \mathrm{C}$ for $3 \mathrm{~h}$ dwell time with a heating/cooling rate of $5^{\circ} \mathrm{C} / \mathrm{min}$ in closed alumina crucibles.

Bulk density was measured with Archimedes' method. An X-ray diffractometer ( XRD, PANalytical, $X^{\prime}$ Pert Pro MPD) was used to study the phase evolution of the ceramics. A scanning electron microscope (SEM, JEOL JSM-6335F) was used to study the microstructure of the ceramics. The grain size of the ceramics was measured using the linear intercept method. Before performing the electrical measurements, all the ceramic samples had been polished into a parallel surface with $1 \mathrm{~mm}$ thickness. Silver paste was painted onto both sides of the pellet. Then, the samples were heated at $700^{\circ} \mathrm{C}$ for $15 \mathrm{~min}$ to form electrodes. For electrical characterizations, dielectric properties as a function of temperature $\left(25-500^{\circ} \mathrm{C}\right)$ were determined using an LCR-meter (HP model 4192A) at frequencies ranging from 1 to $1000 \mathrm{kHz}$. A ferroelectric system based on Radiant Precision High Voltage Interface was used to measure the polarization-electric field (P-E) hysteresis loops at both room temperature (RT) and high temperature (HT) of $25-150^{\circ} \mathrm{C}$. A maximum electric field of $50 \mathrm{kV} / \mathrm{cm}$ and a frequency of $1 \mathrm{~Hz}$ were applied to each sample. $P_{\mathrm{r}}, P_{\max }$, and $E_{\mathrm{c}}$ values were determined from the hysteresis loops. By using data from ferroelectric properties, $W, W_{\text {loss }}$, and $\eta$ values were also calculated.

\section{RESULTS AND DISCUSSION}

\section{Densification, phase formation, and microstructure}

The densification of all ceramics sintered at various sintering temperatures from $1100-1175^{\circ} \mathrm{C}$ are listed in Table 1 . The data clearly showed that the 
Table 1 Physical, phase, microstructure, and electrical properties of 0.7BNT-0.3SBT ceramics sintered at various temperatures.

\begin{tabular}{|c|c|c|c|c|c|c|c|c|c|c|c|}
\hline $\begin{array}{l}\text { Sintering } \\
\text { temp. }\left({ }^{\circ} \mathrm{C}\right)\end{array}$ & $\begin{array}{l}\text { Density } \\
\left(\mathrm{g} / \mathrm{cm}^{3}\right)\end{array}$ & $c / a$ & $\begin{array}{c}\text { Grain } \\
\text { size }(\mu \mathrm{m})\end{array}$ & $\begin{array}{l}T_{\mathrm{F}-\mathrm{R}} \\
\left({ }^{\circ} \mathrm{C}\right)\end{array}$ & $\begin{array}{c}T_{\mathrm{m}} \\
\left({ }^{\circ} \mathrm{C}\right)\end{array}$ & $\begin{array}{c}\varepsilon_{\max } \\
(@ 1 \mathrm{kHz})\end{array}$ & $\begin{array}{c}\tan \delta \\
(@ 1 \mathrm{kHz})\end{array}$ & $\begin{array}{c}P_{\mathrm{r}}^{\mathrm{a}} \\
\left(\mu \mathrm{C} / \mathrm{cm}^{2}\right)\end{array}$ & $\begin{array}{c}E_{\mathrm{c}}{ }^{\mathrm{a}} \\
(\mathrm{kV} / \mathrm{cm})\end{array}$ & $\begin{array}{c}P_{\mathrm{r}}^{\mathrm{b}} \\
\left(\mu \mathrm{C} / \mathrm{cm}^{2}\right)\end{array}$ & $\begin{array}{c}E_{\mathrm{c}}^{\mathrm{b}} \\
(\mathrm{kV} / \mathrm{cm})\end{array}$ \\
\hline 1100 & 5.68 & 1.0100 & 1.28 & 81.12 & 278 & 3249 & 0.0566 & 2.47 & 5.71 & 1.69 & 0.69 \\
\hline 1125 & 5.71 & 1.0094 & 1.54 & 74.61 & 275 & 3320 & 0.0396 & 2.84 & 5.77 & 1.14 & 1.75 \\
\hline 1150 & 5.74 & 1.0084 & 2.02 & 73.80 & 273 & 3510 & 0.0501 & 3.05 & 7.69 & 0.86 & 3.49 \\
\hline 1175 & 5.61 & 1.0076 & 2.51 & 70.61 & 271 & 2921 & 0.0388 & 3.62 & 10.9 & 1.30 & 4.48 \\
\hline
\end{tabular}

${ }^{\mathrm{a}}$ Data obtained at RT and electric field of $50 \mathrm{kV} / \mathrm{cm}$.

${ }^{\mathrm{b}}$ Data obtained at $125^{\circ} \mathrm{C}$ and electric field of $50 \mathrm{kV} / \mathrm{cm}$.

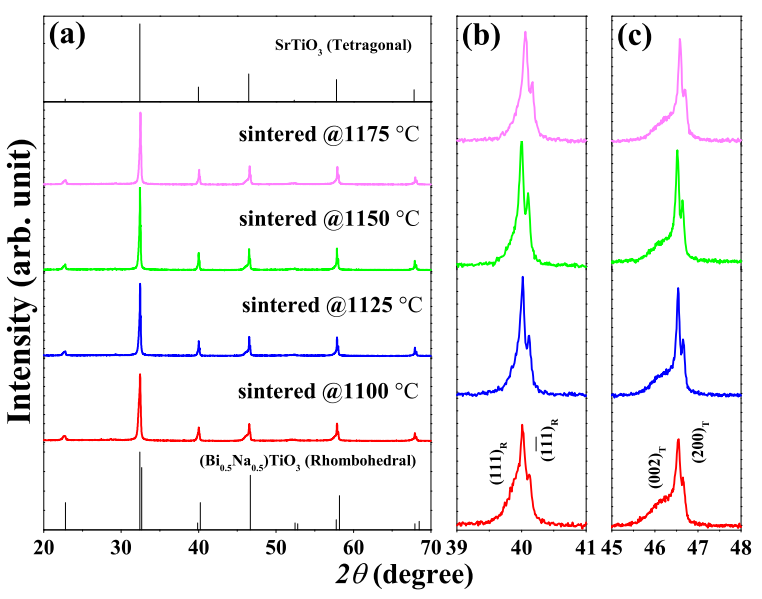

Fig. 1 X-ray diffraction patterns of 0.7BNT-0.3SBT ceramics sintered at various sintering temperatures: (a) $2 \theta=$ $20-70^{\circ}$, (b) $2 \theta=39-41^{\circ}$, and (c) $2 \theta=45-48^{\circ}$.

density was improved by the increase of sintering temperature, and a maximum value of $5.74 \mathrm{~g} / \mathrm{cm}^{3}$ was obtained for the ceramics sintered at $1150^{\circ} \mathrm{C}$. The density was slightly decreased to the minimum value of $5.61 \mathrm{~g} / \mathrm{cm}^{3}$ when the sintering temperature increased to $1175^{\circ} \mathrm{C}$. The reason for the decrease of density value at high temperature was likely due to the evaporation of volatile alkali metal oxides and partial melting at high temperature [15]. In addition, at sintering temperatures lower than $1100^{\circ} \mathrm{C}$, the pellet ceramic samples could not form a ceramic (not dense). Besides, it was found that at high sintering temperature over $1175^{\circ} \mathrm{C}$ (such as $1200^{\circ} \mathrm{C}$ ), the ceramic started to melt and agglomerated with the covered powders into a hard irregular shape object. Thus, the ceramics sintered at $<1100^{\circ} \mathrm{C}$ and $>1175^{\circ} \mathrm{C}$ were excluded from further electrical investigation.

Fig. 1(a) shows the X-ray diffraction patterns of the 0.7BNT-0.3SBT ceramics sintered at various sintering temperatures where $2 \theta=20-70^{\circ}$. For the analysis of phase transition process, the XRD patterns for selected narrow angular ranges of $2 \theta=$ $39-41^{\circ}$ and $2 \theta=45-48^{\circ}$ are presented in Fig. 1(b) and (c), respectively. Within the resolution limit of $\mathrm{XRD}$, all sintered ceramics exhibited a single phase of perovskite structure and no secondary phase could be observed, indicating that SBT completely diffused into the host lattice of BNT [4]. It was possible that a solid solution between BNT and SBT was formed. This was because when the solid solution was made, $\mathrm{Sr}$ ions could replace $\mathrm{Bi}$ and $\mathrm{Na}$ ions, as the ionic radius of $\mathrm{Sr}$ ions (1.44 $\AA$ ) is not much different from the radii of $\mathrm{Bi}(1.40 \AA)$ and $\mathrm{Na}(1.39 \AA)$ ions (percentage of the difference is $2.86-3.59 \%$ ). Moreover, the solubility limit of SBT in BNT lattice was believed to be more than $30 \mathrm{~mol} \%$ because no trace of secondary phases was detected in XRD patterns. All sintered ceramics had a mixed phase of rhombohedral and tetragonal, as evidenced by a slight splitting of rhombohedral $\{111\}$ reflections at $2 \theta=39-41^{\circ}$ and tetragonal $\{200\}$ reflections at $2 \theta=45-48^{\circ}$ [16]. However, sintering temperatures had slight effects on the phase evolution. With increasing sintering temperatures, the cubicrich phase was dominated. This behavior became clearer after the calculated lattice parameters ( $a$ and $c$ ) had been analyses, which indicated a decrease in tetragonality $(c / a)$ (see Table 1 ).

In this study, scanning electron microscope (SEM) was used to determine the morphologies of all the ceramics. The grain size of the ceramics was measured and calculated based on a mean linear interception method. SEM micrographs, with assintered surface mode of the 0.7BNT-0.3SBT ceramic sintered at various sintering temperatures, are shown in Fig. 2. The average grain size values are also summarized in Table 1 . It could be seen that the ceramics' grains displayed well crystallized cubiclike shape with clear boundaries. The grain sizes increased with increasing sintering temperatures, from $1.28 \mu \mathrm{m}$ for the $1100{ }^{\circ} \mathrm{C}$ ceramic to around $2.51 \mu \mathrm{m}$ for the $1175^{\circ} \mathrm{C}$ ceramic. This behavior was in good agreement with other previously reported 


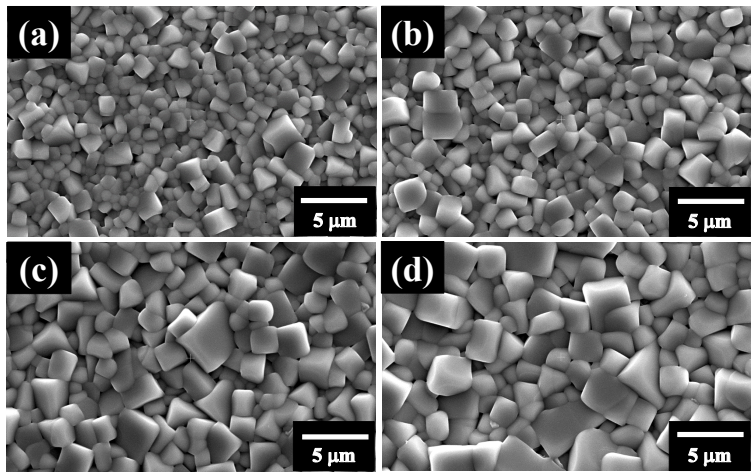

Fig. 2 SEM micrographs, with as-sintered surface mode, of 0.7BNT-0.3SBT ceramics sintered at various sintering temperatures: (a) $1100^{\circ} \mathrm{C}$, (b) $1125^{\circ} \mathrm{C}$, (c) $1150{ }^{\circ} \mathrm{C}$, and (d) $1175^{\circ} \mathrm{C}$.

BNT-based ceramics $[16,17]$, and the reasons for the grain growth could be caused by a mass transfer at grain boundaries and the enhanced diffusion rate by raising sintering temperature [18].

\section{Dielectric properties}

Dielectric constant $\left(\varepsilon_{\mathrm{r}}\right)$ and dielectric loss $(\tan \delta)$ can be used to analyse not only the ferroelectric relaxation properties, but also the phase structure changes by the anomalous points of dielectric curves [19]. Fig. 3 shows temperature dependence on $\varepsilon_{\mathrm{r}}$ and $\tan \delta$ of the poled 0.7BNT-0.3SBT ceramics sintered at various sintering temperatures and measured at various frequencies (from $1-1000 \mathrm{kHz}$ ). In BNT-based materials, two distinctive dielectric anomalies are always discerned [17]. In this study, the result showed that all the ceramic samples also existed at two dielectric peaks referred to as $T_{\mathrm{F}-\mathrm{R}}$ and $T_{\mathrm{m}}$, respectively. The first dielectric anomaly, which involved a frequency dependent dielectric permittivity, and the changes in loss tangent illustrated the relaxor ferroelectrics characteristics [20]. Normally, the lower anomaly peak is located near $T_{\mathrm{F}-\mathrm{R}}$, which is known as the ferroelectric (FE) to ergodic (ER) phase transition temperature [21]. The high temperature anomaly peak is called $T_{\mathrm{m}}$, where the dielectric constant reaches its maximum value $[22,23]$. The sintering temperature has effects on the $T_{\mathrm{F}-\mathrm{R}}, T_{\mathrm{m}}$ and $\varepsilon_{\max }$ values. Fig. 4(a) shows that the ceramics sintered $1100^{\circ} \mathrm{C}$ had $T_{\mathrm{F}-\mathrm{R}}$ and $T_{\mathrm{m}}$ values of $81.12^{\circ} \mathrm{C}$ and $278^{\circ} \mathrm{C}$, respectively. Both $T_{\mathrm{F}-\mathrm{R}}$ and $T_{\mathrm{m}}$ values decreased with increasing sintering temperatures. The downward shift of $T_{\mathrm{F}-\mathrm{R}}$ with increasing sintering temperatures could be a consequence of ferroelectric order destabilization associ- ated with the possible presence of ergodic relaxor (ER) phase in the ceramics [24]. From Fig. 4(b), the ceramic sintered at $1100^{\circ} \mathrm{C}$ had maximum dielectric constant $\left(\varepsilon_{\max }\right)$ of 3249 . The $\varepsilon_{\max }$ increased with increasing sintering temperatures and reached the maximum value of 3510 at $1150^{\circ} \mathrm{C}$. The value was slightly decreased when the sintering temperature was at $1175^{\circ} \mathrm{C}$. Thus, the $\varepsilon_{\max }$ of the ceramics could be improved by increasing the sintering temperature in this system. Normally, electrical properties of many ferroelectric materials can be influenced by many factors including grain size and density. For the grain size effect, it is known that the grain boundary is a low-permittivity region. When the grain size increases, the grain boundary decreases; thus, dielectric constant increases [25]. However, in the present study, the $\varepsilon_{\max }$ of the $1175^{\circ} \mathrm{C}$ ceramic was less than that of the $1150^{\circ} \mathrm{C}$. Thus, the grain size might not be the main factor affecting the dielectric constant (see inset of Fig. 4(b)). Moreover, it was found that the density of the ceramics exhibited the same trend as the $\varepsilon_{\max }$. Therefore, it is believed that the density should be the main factor that affects the dielectric constant. Similar observation in the BNKST ceramics was found by Tho et al [26] who reported that $\varepsilon_{\max }$ increased with increasing sintering temperatures, and the highest $\varepsilon_{\text {max }}$ was obtained at $1100^{\circ} \mathrm{C}$, with maximum density of $5.88 \mathrm{~g} / \mathrm{cm}^{3}$.

\section{Ferroelectric and energy storage density analysis}

The effects of sintering temperatures on polarization-electric field $(P-E)$ hysteresis loop of the 0.7BNT-0.3SBT ceramics were investigated. Fig. 5 shows $P$ - $E$ hysteresis loop of the ceramic sintered at various sintering temperatures, measured at room temperature under an electric field of $50 \mathrm{kV} / \mathrm{cm}$ and a frequency of $1 \mathrm{~Hz}$. The results showed that sintering temperatures had a slight influence on the ferroelectric hysteresis loop shape. However, details of the $P_{\mathrm{r}}$ and $E_{\mathrm{c}}$ are listed in Table 1. All of the ceramics exhibited a pinching in the $P-E$ hysteresis loop at room temperature (RT), which indicated the presence of a mixture of ferroelectric (FE) and ergodic relaxor (ER) phases [27]. It should be noted that the $1150^{\circ} \mathrm{C}$ exhibited a more pronounced pinched loop with low $P_{\mathrm{r}}$. This indicated that the composition of the ceramic samples had higher amount of ER phases. At a low sintering temperature of $1100^{\circ} \mathrm{C}$, the minimum $P_{\mathrm{r}}$ of 2.47 $\mu \mathrm{C} / \mathrm{cm}^{2}$ and $E_{\mathrm{c}}$ of $5.71 \mathrm{kV} / \mathrm{cm}$ were observed. The $P_{\mathrm{r}}$ and $E_{\mathrm{c}}$ values increased with increasing sintering 

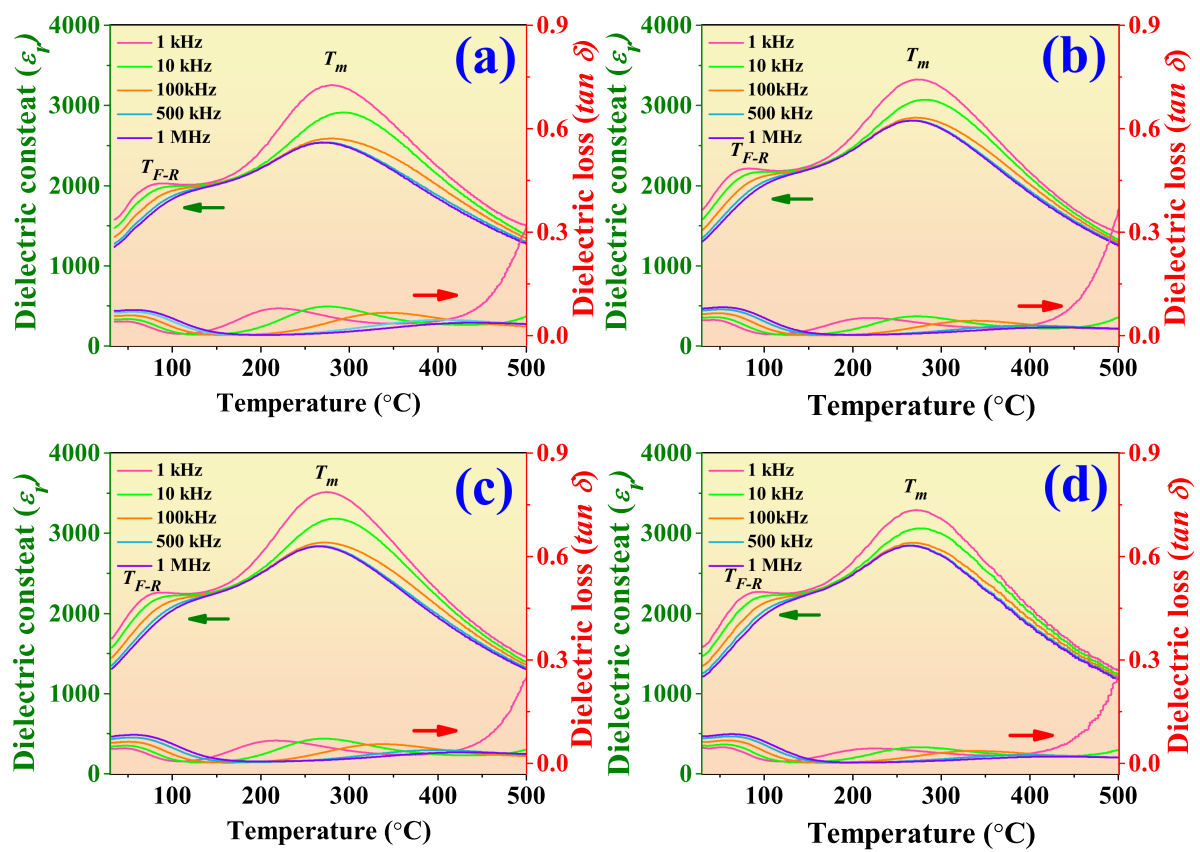

Fig. 3 Temperature dependence on dielectric constant $\left(\varepsilon_{\mathrm{r}}\right)$ and dielectric loss $(\tan \delta)$ of poled 0.7BNT-0.3SBT ceramics sintered at various sintering temperatures, measured at various frequencies from 1-1000 kHz: (a) $1100^{\circ} \mathrm{C}$, (b) $1125^{\circ} \mathrm{C}$, (c) $1150^{\circ} \mathrm{C}$, and (d) $1175^{\circ} \mathrm{C}$.
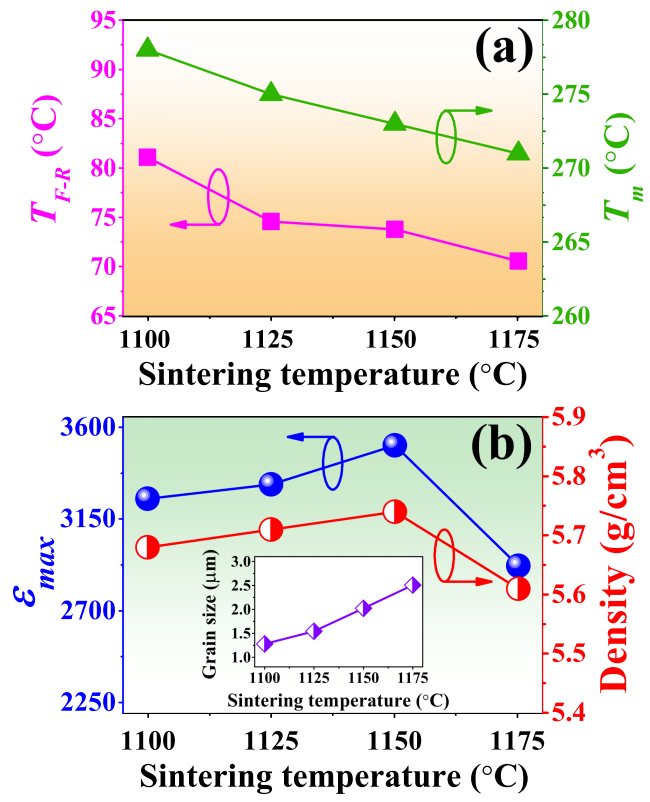

Fig. 4 Plots of (a) $T_{\mathrm{F}-\mathrm{R}}$ and $T_{\mathrm{m}} @ 1 \mathrm{kHz}$ as a function of sintering temperatures and (b) $\varepsilon_{\max } @ 1 \mathrm{kHz}$ and density values as a function of sintering temperatures of 0.7BNT-0.3SBT ceramics sintered at various sintering temperatures (inset: grain sizes as a function of sintering temperatures).
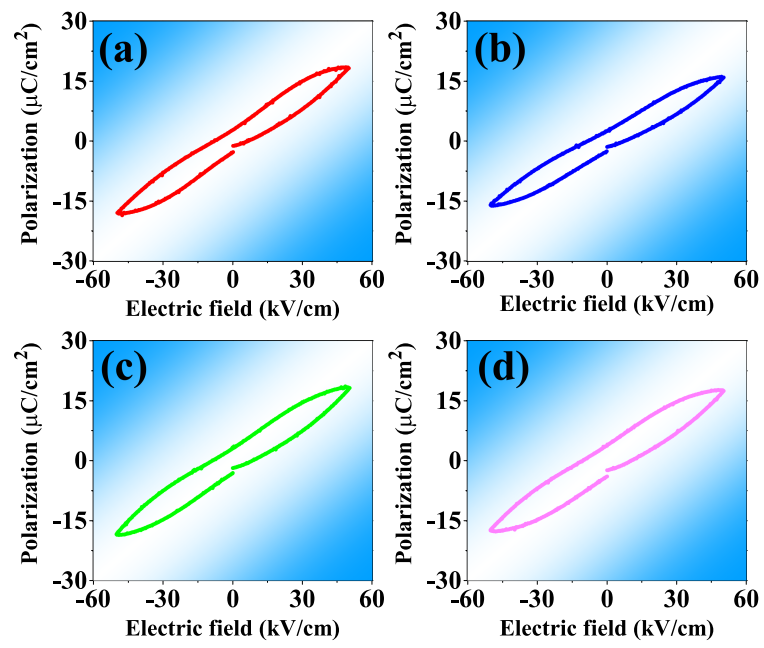

Fig. 5 Polarization-electric field $(P-E)$ hysteresis loop of $0.7 \mathrm{BNT}-0.3 \mathrm{SBT}$ ceramics sintered at various sintering temperatures, measured at RT under an electric field of 50 $\mathrm{kV} / \mathrm{cm}$ and a frequency of $1 \mathrm{~Hz}$ : (a) $1100^{\circ} \mathrm{C}$, (b) $1125^{\circ} \mathrm{C}$, (c) $1150^{\circ} \mathrm{C}$, and (d) $1175^{\circ} \mathrm{C}$.

temperatures and respectively showed the maximum value of $3.62 \mu \mathrm{C} / \mathrm{cm}^{2}$ and $10.90 \mathrm{kV} / \mathrm{cm}$ for the $1175^{\circ} \mathrm{C}$ ceramic. The increasing $P_{\mathrm{r}}$ value in this study could be due to the increasing grain size caused by the sintering temperature. Normally, the 


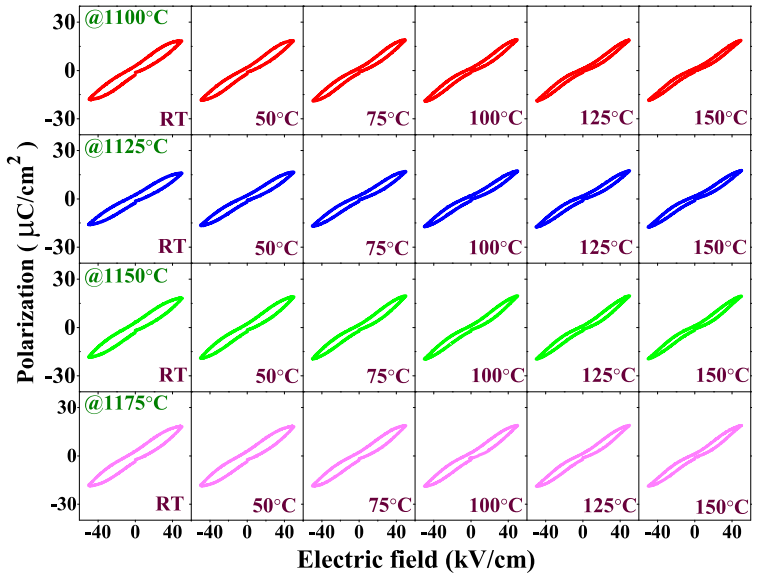

Fig. 6 Temperature dependence on polarization-electric field $(P-E)$ hysteresis loops of 0.7BNT-0.3SBT ceramics sintered at various sintering temperatures, measured under an electric field of $50 \mathrm{kV} / \mathrm{cm}$ and a frequency of $1 \mathrm{~Hz}$.

grain boundary is a low-permittivity region. That means the grain boundary has poor ferroelectricity. The number of grain boundary decreases as grain size increases, thus, $P_{\mathrm{r}}$ value increases [25]. Similar results were observed in the $\mathrm{Ba}_{0.8} \mathrm{Sr}_{0.2} \mathrm{TiO}_{3}$ ceramics studied by Mudinepalli et al [25] who found that the $P_{\mathrm{r}}$ increased with increasing grain size and sintering temperature. Tan et al [28] also found the $P_{\max }$ and $P_{\mathrm{r}}$ slightly increased with increasing grain size for $\mathrm{BaTiO}_{3}$ ceramic prepared by spark plasma sintering method (SPS).

Temperature dependence on polarizationelectric field $(P-E)$ hysteresis loops of the 0.7BNT$0.3 \mathrm{SBT}$ ceramics sintered at various sintering temperatures, measured under an electric field of $50 \mathrm{kV} / \mathrm{cm}$ and a frequency of $1 \mathrm{~Hz}$ are depicted in Fig. 6. All 0.7BNT-0.3SBT ceramics already exhibited ergodic relaxor (ER) characteristic at RT. When the temperature increased, the $P$-E hysteresis loops became more pinched, confirming that the ferroelectric to relaxor phase transition was induced by thermal activation, thus leaving an ergodic relaxor (ER) state at zero electric field [29]. The drastic decrease in both $P_{\mathrm{r}}$ and $E_{\mathrm{c}}$ values might also be related to the onset of strong ergodicity [30].

As a rule, the pinched $P-E$ loop is always good for improving recoverable energy storage density in dielectric materials [4]. To evaluate the practicability of these ceramics for energy storage systems, the energy storage density $(W)$ and energy storage efficiencies $(\eta)$ of the studied ceramics were calculated
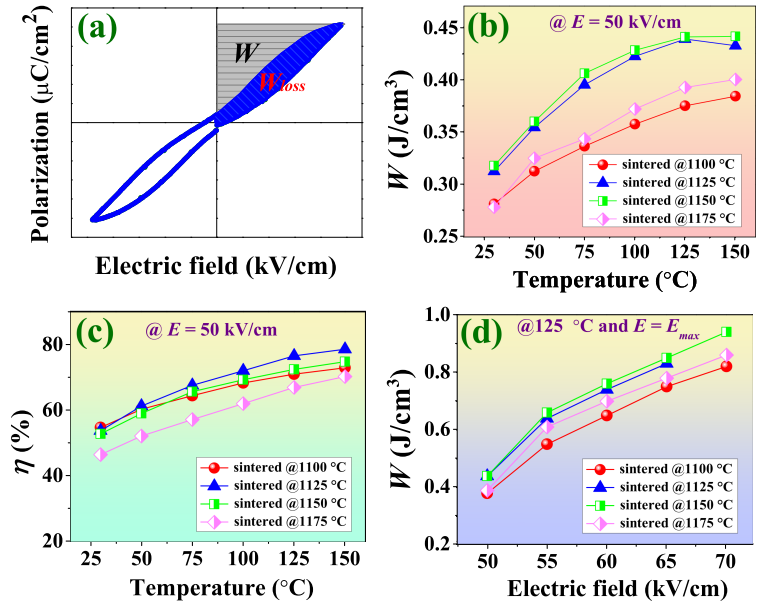

Fig. 7 Plots of (a) schematics calculation of $W$ and $W_{\text {loss }}$ values, (b) $W$ as a function of temperatures (@E $=50$ $\mathrm{kV} / \mathrm{cm}$ ), (c) $\eta$ as a function of temperatures (@E $=50$ $\mathrm{kV} / \mathrm{cm}$ ), and (d) $W @ 125^{\circ} \mathrm{C}$ as a function of electric field (until breakdown strength reached) of 0.7BNT-0.3SBT ceramics sintered at various sintering temperatures.

Table 2 Energy storage properties of 0.7BNT-0.3SBT ceramics sintered at various temperatures.

\begin{tabular}{lcccccc}
\hline $\begin{array}{l}\text { Sintering } \\
\text { temp. }\left({ }^{\circ} \mathrm{C}\right)\end{array}$ & $\begin{array}{c}W^{\mathrm{a}} \\
\left(\mathrm{J} / \mathrm{cm}^{3}\right)\end{array}$ & $\begin{array}{c}\eta^{\mathrm{a}} \\
(\%)\end{array}$ & $\begin{array}{c}W^{\mathrm{b}} \\
\left(\mathrm{J} / \mathrm{cm}^{3}\right)\end{array}$ & $\begin{array}{c}\eta^{\mathrm{b}} \\
(\%)\end{array}$ & $\begin{array}{c}W^{\mathrm{c}} \\
\left(\mathrm{J} / \mathrm{cm}^{3}\right)\end{array}$ & $\begin{array}{c}\eta^{\mathrm{c}} \\
(\%)\end{array}$ \\
\hline 1100 & 0.28 & 54.81 & 0.38 & 71.02 & 0.82 & 81.21 \\
1125 & 0.31 & 53.83 & 0.44 & 76.59 & 0.83 & 84.11 \\
1150 & 0.32 & 52.91 & 0.44 & 72.51 & 0.94 & 89.93 \\
1175 & 0.28 & 46.61 & 0.39 & 67.03 & 0.86 & 87.90 \\
\hline
\end{tabular}

${ }^{\text {a }}$ Data obtained at RT and electric field of $50 \mathrm{kV} / \mathrm{cm}$.

${ }^{b}$ Data obtained at $125^{\circ} \mathrm{C}$ and electric field of $50 \mathrm{kV} / \mathrm{cm}$.

${ }^{\mathrm{c}}$ Data obtained at $125^{\circ} \mathrm{C}$ and the maximum electric field.

from the $P$-E loops using the following equations $[4,31,32]$ :

$$
\begin{gathered}
W=\int_{P_{\mathrm{r}}}^{P_{\max }} E \mathrm{~d} P, \\
\eta=\frac{W}{W-W_{\text {loss }}} \times 100,
\end{gathered}
$$

where $E$ is the electric field, $P$ is the polarization, $P_{\max }$ is the maximum polarization, $P_{\mathrm{r}}$ is the remnant polarization, and energy loss density is denoted as $W_{\text {loss }}[4,31,32]$. In this study, the schematics calculation of $W$ and $W_{\text {loss }}$ values could be obtained from Fig. 7(a). Plots of $W$ and $\eta$ values as a function of the temperatures (at $E=50 \mathrm{kV} / \mathrm{cm}$ ) of all studied ceramics are shown in Fig. 7(b) and Fig. 7(c), respectively. The related energy storage values are also summarized in Table 2 . The $W$ and $\eta$ values of all ceramics increased with increasing 
temperatures from RT $\left(25^{\circ} \mathrm{C}\right)$ to $\mathrm{HT}\left(150^{\circ} \mathrm{C}\right.$ ) (see Fig. 7(b) and Fig. 7(c)). At the applied electric field of $50 \mathrm{kV} / \mathrm{cm}$ and at RT, the $W$ and $\eta$ values increased with increasing sintering temperatures and respectively reached the maximum values of $0.32 \mathrm{~J} / \mathrm{cm}^{3}$ and $52.91 \%$ at $1150^{\circ} \mathrm{C}$. At the higher sintering temperature of $1175^{\circ} \mathrm{C}$, the $W$ and $\eta$ values slightly decreased.

Similarly, at the applied electric field of 50 $\mathrm{kV} / \mathrm{cm}$ and at $125^{\circ} \mathrm{C}$, the $W$ and $\eta$ values of the ceramics increased with increasing sintering temperatures and respectively reached the maximum values of $0.44 \mathrm{~J} / \mathrm{cm}^{3}$ and $71.51 \%$ at $1150^{\circ} \mathrm{C}$. In addition, plots of the $W$ values obtained at $125^{\circ} \mathrm{C}$ as a function of the electric field (until breakdown strength was reached) are shown in Fig. 7(d). At the maximum electric field and $125^{\circ} \mathrm{C}$, the ceramic sintered at $1150^{\circ} \mathrm{C}$ showed the maximum values of $W$ and $\eta$ of $0.94 \mathrm{~J} / \mathrm{cm}^{3}$ and $89.93 \%$, respectively. Yu et al [33] have pointed out that grain size is a factor that affects the $W$ value. However, the reason for the improvement of $W$ of the $1150^{\circ} \mathrm{C}$ ceramics in this study was likely due to the lower $P_{\mathrm{r}}$ value when compared with those of other samples (Table 1); and the lower $P_{\mathrm{r}}$ value could be a result of the higher ER phase.

Based on our results, it could be suggested that the optimum sintering temperature for preparing ceramics with high density and electrical properties, i.e. dielectric and energy storage density, was $1150^{\circ} \mathrm{C}$, and the $1150^{\circ} \mathrm{C}$ ceramic could be considered as one of promising candidate materials for the production of high energy density devices.

\section{CONCLUSION}

In this study, the $0.7 \mathrm{Bi}_{0.5} \mathrm{Na}_{0.5} \mathrm{TiO}_{3}-0.3 \mathrm{Sr}_{0.7} \mathrm{Bi}_{0.2}$ $\mathrm{TiO}_{3}$, or 0.7BNT-0.3SBT, ceramics sintered at various sintering temperatures were successfully synthesized by a conventional mixed oxide method. The processing sintering temperature had a strong effect on microstructure, dielectric, ferroelectric, and energy storage density properties of the ceramics. The optimum sintering temperature for preparing ceramics with high densification and electrical performance was $1150^{\circ} \mathrm{C}$. Grain size values increased with increasing sintering temperature. The ceramic sintered at $1150^{\circ} \mathrm{C}$ showed good densification (bulk density $\left.=5.74 \mathrm{~g} / \mathrm{cm}^{3}\right)$, dielectric $\left(\varepsilon_{\max }=\right.$ $\left.3510, \tan \delta=0.0501, T_{\mathrm{F}-\mathrm{R}}=73.80^{\circ} \mathrm{C}, T_{\mathrm{m}}=273^{\circ} \mathrm{C}\right)$, ferroelectric $\left(P_{\mathrm{r}}=3.05 \mu \mathrm{C} / \mathrm{cm}^{2}, E_{\mathrm{c}}=7.69 \mathrm{kV} / \mathrm{cm}\right)$, and energy storage properties $\left(W=0.94 \mathrm{~J} / \mathrm{cm}^{3}, \eta\right.$ $=89.93 \%$ at $125^{\circ} \mathrm{C}$ and maximum electric field). Based on our results, the sintering temperature for preparing ceramics with high density and high electrical and energy storage density properties was $1150^{\circ} \mathrm{C}$.

Acknowledgements: This study was supported by the Chiang Mai University and National Research Council of Thailand (NRCT). Research Center in Physics and Astronomy, Materials Science Research Center, Basic Research Fund, Global Partnership Project, Department of Physics and Materials Science, Science and Technology Research Institute, and Graduate School, Chiang Mai University are also acknowledged.

\section{REFERENCES}

1. Yang H, Yan F, Lin Y, Wang T, He L, Wang F (2017) A lead free relaxation and high energy storage efficiency ceramics for energy storage applications. $J$ Alloys Compd 710, 436-445.

2. Xu Q, Li T, Hao H, Zhang S, Wang Z, Cao M, Yao Z, Liu H (2015) Enhanced energy storage properties of $\mathrm{NaNbO}_{3}$ modified $\mathrm{Bi}_{0.5} \mathrm{Na}_{0.5} \mathrm{TiO}_{3}$ based ceramics. $J$ Eur Ceram Soc 35, 545-553.

3. Li Q, Yao Z, Ning L, Gao S, Hu B, Dong G, Fan $\mathrm{H}$ (2018) Enhanced energy-storage properties of $(1-x)\left(0.7 \mathrm{Bi}_{0.5} \mathrm{Na}_{0.5} \mathrm{TiO}_{3}-0.3 \mathrm{Bi}_{0.2} \mathrm{Sr}_{0.7} \mathrm{TiO}_{3}\right)-x \mathrm{NaNbO}_{3}$ lead-free ceramics. Ceram Int 44, 2782-2788.

4. Qiao X, Wu D, Zhang F, Niu M, Chen B, Zhao X, Liang P, Wei L, et al (2019) Enhanced energy density and thermal stability in relaxor ferroelectric $\mathrm{Bi}_{0.5} \mathrm{Na}_{0.5} \mathrm{TiO}_{3}-\mathrm{Sr}_{0.7} \mathrm{Bi}_{0.2} \mathrm{TiO}_{3}$ ceramics. $J$ Eur Ceram Soc 39, 4778-4784.

5. Li QN, Zhou CR, Xu JW, Yang L, Zhang X, Zeng WD, Yuan CL, Chen GH, et al (2016) Ergodic relaxor state with high energy storage performance induced by doping $\mathrm{Sr}_{0.85} \mathrm{Bi}_{0.1} \mathrm{TiO}_{3}$ in $\mathrm{Bi}_{0.5} \mathrm{Na}_{0.5} \mathrm{TiO}_{3}$ ceramics. $J$ Electron Mater 45, 5146-5151.

6. Jaita P, Jarupoom P (2020) Temperature dependence on structure, mechanical and electrical properties of bismuth lanthanum sodium titanate-modified lead zirconate titanate ceramics. ScienceAsia 46S, 51-57.

7. Jaita P, Sanjoom R, Lertcumfu N, Malasri P, Rujijangul G, Tunkasiri T (2020) Effect of barium iron tantalate incorporation on mechanical, electrical, and magnetocapacitance properties of modified bismuth sodium potassium titanate ceramics. ScienceAsia 46S, 66-73.

8. Yin J, Zhang YX, Lv X, Wu JG (2018) Ultrahigh energy-storage potential under low electric field in bismuth sodium titanate-based perovskite ferroelectrics. J Mater Chem A6, 9823-9832.

9. Qiao X, Zhang F, Wu D, Chen B, Zhao X, Peng Z, Ren X, Liang P, et al (2020) Superior comprehensive energy storage properties in $\mathrm{Bi}_{0.5} \mathrm{Na}_{0.5} \mathrm{TiO}_{3}$-based relaxor ferroelectric ceramics. Chem Eng $J$ 388, ID 124158.

10. Hu B, Fan H, Ning L, Gao S, Yao Z, Li Q (2018) Enhanced energy-storage performance and dielectric 
temperature stability of $(1-x)\left(0.65 \mathrm{Bi}_{0.5} \mathrm{Na}_{0.5} \mathrm{TiO}_{3}\right.$ $\left.0.35 \mathrm{Bi}_{0.1} \mathrm{Sr}_{0.85} \mathrm{TiO}_{3}\right)-x \mathrm{KNbO}_{3}$ ceramics. Ceram Int 44, 10968-10974.

11. Zhao P, Tang B, Si F, Yang C, Li H, Zhang S (2020) Novel Ca doped $\mathrm{Sr}_{0.7} \mathrm{Bi}_{0.2} \mathrm{TiO}_{3}$ lead-free relaxor ferroelectrics with high energy density and efficiency. $J$ Eur Ceram Soc 40, 1938-1946.

12. Chen A, Zhi Y (2002) Dielectric relaxor and ferroelectric relaxor: Bi-doped paraelectric $\mathrm{SrTiO}_{3}$. J Appl Phys 91, ID 1487.

13. Ang C, Yu Z (2010) Dielectric and ferroelectric properties in ( $\mathrm{Sr}, \mathrm{Ni}, \mathrm{Na}) \mathrm{TiO}_{3}$ solid solutions. J Appl Phys 107, ID 114106.

14. Jaiban P, Jiansirisomboon S, Watcharapasorn A (2011) Densification of $\mathrm{Bi}_{0.5} \mathrm{Na}_{0.5} \mathrm{ZrO}_{3}$ ceramic using liquid-phase sintering method. ScienceAsia 37, 256-261.

15. Moulson AJ, Herbert JM (1996) Electroceramics, Chapman and Hall Press, New York, USA.

16. Dung DD, Quyet NV, Bac LH (2015) Role of sintering temperature on giant fieldinduced strain in lead-free $\mathrm{Bi}_{0.5}(\mathrm{NaK})_{0.5} \mathrm{TiO}_{3}$-based ceramics. Ferroelectrics 474, 113-119.

17. Bac DLH, Hong HS, Odkhuu D, Dung DD (2016) Effect of sintering temperature on properties of leadfree piezoelectric $0.975 \mathrm{Bi}_{0.5}\left(\mathrm{Na}_{0.82} \mathrm{~K}-0.18\right)_{0.5} \mathrm{TiO}_{3}$ $0.025 \mathrm{LiTaO}_{3}$ ceramics. J Nanosci Nanotechnol 16, 7929-7934.

18. Callister WD, Rethwisch DG (2003) Materials Science and Engineering: An Introduction, Wiley, New York, USA.

19. Zhao N, Fan H, Ma J, Ren X, Shi Y, Zhou Y (2018) Large strain of temperature insensitive in (1- $x$ ) $\left(0.94 \mathrm{Bi}_{0.5} \mathrm{Na}_{0.5} \mathrm{TiO}_{3}-0.06 \mathrm{BaTiO}_{3}\right)-x \mathrm{Sr}_{0.7} \mathrm{La}_{0.2} \mathrm{TiO}_{3}$ lead-free ceramics. Ceram Int 44, 11331-11339.

20. Shi J, Fan H, Liu X, Ma Y, Li Q (2015) Bi deficiencies induced high permittivity in lead-free BNBT-BST high-temperature dielectrics. J Alloys Compd 627, 463-467.

21. Ge RF, Zhao ZH, Duan SF, Kang XY, Lv YK, Yin DS, Dai Y (2017) Large electro-strain response of $\mathrm{La}^{3+}$ and $\mathrm{Nb}^{5+}$ co-doped ternary $0.85 \mathrm{Bi}_{0.5} \mathrm{Na}_{0.5} \mathrm{TiO}_{3}$ $0.11 \mathrm{Bi}_{0.5} \mathrm{~K}_{0.5} \mathrm{TiO}_{3}-0.04 \mathrm{BaTiO}_{3}$ lead-free piezoelectric ceramics. J Alloys Compd 724, 1000-1006.

22. Lv YK, Duan SF, Zhao ZH, Kang XY, Ge RF, Wang H, Dai Y (2018) Enhanced electromechanical strain response in $\left(\mathrm{Fe}_{0.5} \mathrm{Nb}_{0.5}\right)^{4+}$-modified $\mathrm{Bi}_{0.5}\left(\mathrm{Na}_{0.8} \mathrm{~K}_{0.2}\right)_{0.5} \mathrm{TiO}_{3}$ lead-free piezoelectric ceramics. J Mater Sci 53, 8059-8066.
23. Malik RA, Hussain A, Maqbool A, Zaman A, Ahn CW, Rahman JU, Song TK, Kim WJ, et al (2015) Temperature-insensitive high strain in lead-free $\mathrm{Bi}_{0.5}\left(\mathrm{Na}_{0.84} \mathrm{~K}_{0.16}\right)_{0.5} \mathrm{TiO}_{3}-0.04 \mathrm{SrTiO}_{3}$ ceramics for actuator applications. J Am Ceram Soc 98, 3842-3848.

24. Hao J, Xu Z, Chu R, Li W, Fu P, Du J, Li G (2016) Structure evolution and electrostrictive properties in $\left(\mathrm{Bi}_{0.5} \mathrm{Na}_{0.5}\right)_{0.94} \mathrm{Ba}_{0.06} \mathrm{TiO}_{3}-\mathrm{M}_{2} \mathrm{O}_{5}(\mathrm{M}=\mathrm{Nb}$, $\mathrm{Ta}, \mathrm{Sb}$ ) lead-free piezoceramics. J Eur Ceram Soc 36, 4003-4014.

25. Mudinepalli VR, Feng L, Lin WC, Murty BS (2015) Effect of grain size on dielectric and ferroelectric properties of nanostructured $\mathrm{Ba}_{0.8} \mathrm{Sr}_{0.2} \mathrm{TiO}_{3}$ ceramics. $J$ Adv Ceram 4, 46-53.

26. Tho NT, Vuong LD (2020) Effect of sintering temperature on the dielectric, ferroelectric and energy storage properties of $\mathrm{SnO}_{2}$-doped $\mathrm{Bi}_{0.5}\left(\mathrm{Na}_{0.8} \mathrm{~K}_{0.2}\right)_{0.5} \mathrm{TiO}_{3}$ lead-free ceramics. J Adv Ceram 4, ID 2050011.

27. Dinh TH, Kang JK, Lee JS, Khansur NH, Daniels J, Lee HY, Yao FZ, Wang K, et al (2016) Nanoscale ferroelectric/relaxor composites: Origin of large strain in lead-free Bi-based incipient piezoelectric ceramics. $J$ Euro Ceram Soc 36, 3401-3407.

28. Tan Y, Zhang J, Wu Y, Wang C, Koval V, Shi B, Ye H, McKinnon R, et al (2015) Unfolding grain size effects in barium titanate ferroelectric ceramics. Sci Rep 5, ID 9953.

29. Wang K, Hussain A, Jo W, Rödel J (2012) Temperature-dependent properties of $\left(\mathrm{Bi}_{1 / 2} \mathrm{Na}_{1 / 2}\right) \mathrm{TiO}_{3}$ $\left(\mathrm{Bi}_{1 / 2} \mathrm{~K}_{1 / 2}\right) \mathrm{TiO}_{3}-\mathrm{SrTiO}_{3}$ lead-free piezoceramics. J Am Ceram Soc 95, 2241-2247.

30. Malik RA, Hussain A, Maqbool A, Zaman A, Song TK, Kim WJ, Kim MH (2016) Giant strain, thermallystable high energy storage properties and structural evolution of Bi-based lead-free piezoceramics. $J$ Alloys Compd 682, 302-310.

31. Zhao Y, Xu J, Yang L, Zhou C, Lu X, Yuan C, Li Q, Chen $G$, et al (2016) High energy storage property and breakdown strength of $\mathrm{Bi}_{0.5}\left(\mathrm{Na}_{0.82} \mathrm{~K}_{0.18}\right)_{0.5} \mathrm{TiO}_{3}$ ceramics modified by $\left(\mathrm{Al}_{0.5} \mathrm{Nb}_{0.5}\right)^{4+}$ complexion. $J$ Alloys Compd 666, 209-216.

32. Hu B, Fan $\mathrm{H}$, Ning $\mathrm{L}$, Wen $\mathrm{Y}$, Wang $\mathrm{C}$ (2018) High energy storage performance of $\left[\left(\mathrm{Bi}_{0.5} \mathrm{Na}_{0.5}\right)_{0.94} \mathrm{Ba}_{0.06}\right]_{0.97} \mathrm{La}_{0.0} \mathrm{Ti}_{1-x}\left(\mathrm{Al}_{0.5} \mathrm{Nb}_{0.5}\right)_{\mathrm{x}} \mathrm{O}_{3}$ ceramics with enhanced dielectric breakdown strength. Ceram Int 44, 15160-15166.

33. Yu Z, Zeng J, Zheng L, Rousseau A, Li G, Kassi A (2021) Microstructure effects on the energy storage density in $\mathrm{BiFeO}_{3}$-based ferroelectric ceramics. Ceram Int 47, 12735-12741. 